\title{
Ancient mantle heterogeneities recorded in igneous and sedimentary rocks
}

VINCIANE DEBAILLE ${ }^{1}$, ASHLEA WAINWRIGHT ${ }^{2}$, DR. J. ELIS HOFFMANN $^{3}$, SEBASTIAN VIEHMANN ${ }^{4}$ AND MICHAEL BAU 5

${ }^{1}$ Université Libre de Bruxelles.

${ }^{2}$ The University of Melbourne

${ }^{3}$ Freie Universität Berlin

${ }^{4}$ University of Vienna

${ }^{5}$ Jacobs University Bremen

Presenting Author: vinciane.debaille@ulb.be

Even though the first 500 million years of geological record are missing on the surface of the Earth, early planetary evolution can still be evidenced by short-lived isotope systems that were extant at that time. Notably, the ${ }^{146} \mathrm{Sm}-{ }^{142} \mathrm{Nd}$ system is a powerful tool for unravelling early differentiation of the Earth. Positive and negative anomalies in ${ }^{142} \mathrm{Nd}$ have been widely documented during the Archean (4 to 2.5 billion years (Gyr) ago), the youngest one being identified at $2.7 \mathrm{Gyr}$ in the Abitibi Greenstone Belt in the Canadian Shield (Theo's flow) [1].

Observations of those anomalies are paradoxical because the terrestrial internal heat was much higher during the Archean, implying that the mantle was convecting faster, resulting in faster mixing time of those early anomalies. Preservation of chemical heterogeneities in a convecting Archean mantle has been modeled, suggesting that inefficient convective mixing can occur even in a highly convective mantle in absence of plate tectonics, i.e. in a stagnant-lid regime, with only short and sporadic subduction episodes [1].

Remarkably, ${ }^{142} \mathrm{Nd}$ anomalies have been found in the Neoarchean Temagami banded iron formation (BIF), which is an archive of local seawater of the Canadian Shield $2.7 \mathrm{Ga}$ ago. Magnetite layers, formed from seawater dominated by strong volcanic input through submarine hydrothermalism, display the same positive anomaly as shown by the contemporaneous Theo's flow, corroborating their mantle origin. In contrast, the metachert layers, which precipitated from seawater during times of dominant continental input, show much lower ${ }^{142} \mathrm{Nd}$ within the present-day range, reflecting a mixture between hydrothermal $\mathrm{Nd}$ of mantle origin and continental $\mathrm{Nd}$. Because the ${ }^{142} \mathrm{Nd}$ value resulting from the mixing is lower, it means one of its endmembers taps into a reservoir that differentiated while ${ }^{146} \mathrm{Sm}$ was extant and with a lower than chondritic $\mathrm{Sm} / \mathrm{Nd}$ ratio. As such, BIFs have the potential to simultaneously trace the ${ }^{142} \mathrm{Nd}$ signature of the upper mantle and eroding continents throughout the Precambrian.

This illustrates not only the strength of short-lived radiogenic systems in tracking ancient heterogeneities, but also how they can be preserved through various geological processes.

[1] Debaille et al., (2013), EPSL 373, 83-92 